\title{
BMJ Global Health The COVID-19 pandemic and healthcare systems in Africa: a scoping review of preparedness, impact and response
}

Gizachew A Tessema (D) ,,2 Yohannes Kinfu, ${ }^{3,4}$ Berihun Assefa Dachew, ${ }^{1,5}$ Azeb Gebresilassie Tesema (10 , ,7 Yibeltal Assefa (D) , ${ }^{8}$ Kefyalew Addis Alene, ${ }^{1,9}$ Atsede Fantahun Aregay, ${ }^{10,11}$ Mohammed Biset Ayalew, ${ }^{12,13}$ Woldesellassie M Bezabhe, ${ }^{14}$ Ayele Geleto Bali, ${ }^{15,16}$ Abel Fekadu Dadi, ${ }^{5,17}$ Bereket Duko, ${ }^{1,18}$ Daniel Erku, ${ }^{19,20}$ Kahsu Gebrekidan, ${ }^{10}$

Kidane Tadesse Gebremariam, ${ }^{7,21}$ Lemlem Gebremedhin Gebremichael, ${ }^{22,23}$ Eyob Alemayehu Gebreyohannes, ${ }^{24}$ Yalemzewod Assefa Gelaw, ${ }^{5,9,25}$ Hailay Abrha Gesesew, ${ }^{26,27}$ Getiye Dejenu Kibret, ${ }^{28,29}$ Cheru Tesema Leshargie, ${ }^{30,31}$ Maereg Wagnew Meazew (D) ,"32 Alemayehu Mekonnen, ${ }^{33,34}$ Alemnesh H. Mirkuzie, ${ }^{35,36}$ Hassen Mohammed, ${ }^{37,38}$ Dejen Yemane Tekle, ${ }^{6,7}$ Fisaha Haile Tesfay ${ }^{7,39,40}$

To cite: Tessema GA, Kinfu Y, Dachew BA, et al. The COVID-19 pandemic and healthcare systems in Africa: a scoping review of preparedness, impact and response. BMJ Global Health 2021;6:e007179. doi:10.1136/ bmjgh-2021-007179

\section{Handling editor Sanni Yaya}

Received 12 August 2021 Accepted 19 November 2021

\section{Check for updates}

(C) Author(s) (or their employer(s)) 2021. Re-use permitted under CC BY-NC. No commercial re-use. See rights and permissions. Published by BMJ.

For numbered affiliations see end of article.

Correspondence to Dr Gizachew A Tessema; gizachew.tessema@curtin. edu.au

\section{ABSTRACT}

Background The COVID-19 pandemic has overwhelmed health systems in both developed and developing nations alike. Africa has one of the weakest health systems globally, but there is limited evidence on how the region is prepared for, impacted by and responded to the pandemic. Methods We conducted a scoping review of PubMed, Scopus, CINAHL to search peer-reviewed articles and Google, Google Scholar and preprint sites for grey literature. The scoping review captured studies on either preparedness or impacts or responses associated with COVID-19 or covering one or more of the three topics and guided by Arksey and 0'Malley's methodological framework. The extracted information was documented following the Preferred Reporting Items for Systematic Reviews and Meta-Analyses extension checklist for scoping reviews. Finally, the resulting data were thematically analysed.

Results Twenty-two eligible studies, of which 6 reported on health system preparedness, 19 described the impacts of COVID-19 on access to general and essential health services and 7 focused on responses taken by the healthcare systems were included. The main setbacks in health system preparation included lack of available health services needed for the pandemic, inadequate resources and equipment, and limited testing ability and surge capacity for COVID-19. Reduced flow of patients and missing scheduled appointments were among the most common impacts of the COVID-19 pandemic. Health system responses identified in this review included the availability of telephone consultations, re-purposing of available services and establishment of isolation centres, and provisions of COVID-19 guidelines in some settings. Conclusions The health systems in Africa were inadequately prepared for the pandemic, and its impact was substantial. Responses were slow and did not match the magnitude of the problem. Interventions that will

\section{Key questions}

What is already known?

- COVID-19 affects people of all ages, however, older people, and those with underlying medical conditions are at greater risk of infection and mortality from the disease.

- Despite the slow progress of the COVID-19 pandemic in Africa, there is increasing concern about the impact as nearly all countries in the region have weak healthcare systems.

What are the new findings?

- Africa's health systems were not well prepared for the pandemic.

- The response was generally slow and disproportionate to the magnitude of the problem.

- The pandemic had sizeable adverse effects on access to and utilisation of essential services.

What do the new findings imply?

- Efforts should be directed toward building health system resilience through local, national and global engagement and improving healthcare financing.

- African countries should focus on a coordinated approach to build capacity for vaccine development, transport and roll-out of vaccination for healthcare professionals and high-risk individuals, including rural areas.

- High-quality time-trend analyses are needed to understand better the extent and nature of ongoing changes and responses of the African health systems to the pandemic.

improve and strengthen health system resilience and financing through local, national and global engagement should be prioritised. 


\section{INTRODUCTION}

COVID-19, caused by a novel SARS-COV-2, continues to create havoc across the globe. ${ }^{12}$ COVID-19 affects people of all ages; however, older people; and those with underlying medical conditions are at greater risk of infection and mortality from the disease. ${ }^{2}$ As of 26 October 2021, over 244 million people were infected by the virus, and the COVID-19 pandemic caused 4.95 million deaths globally. Africa alone registered an estimated 8.5 million COVID-19 infections and over 217000 deaths. ${ }^{3}$ Despite the late start and slow progress of the COVID-19 pandemic in Africa, there is increasing concern about the impact of the pandemic as nearly all countries in the region have weak healthcare systems. ${ }^{4}$

Africa has limited health infrastructure and workforce, including a shortage of professionals trained in critical care and inadequate tertiary care facilities (specialised hospitals) equipped with intensive care units (ICUs). ${ }^{5}$ In urban areas of Africa, health facilities are overcrowded with patients due to staff shortages, while in rural areas, unreliable transport and poor roads infrastructure remain key bottlenecks for access to medical care. ${ }^{4}$

The World Health Organization (WHO) recommends regular hand washing, face masks, social distancing and covering the mouth and nose while coughing or sneezing to prevent transmission of the virus. ${ }^{67}$ However, these measures mainly depend on how individuals respond to advice. ${ }^{8}$ Furthermore, resource scarcity could further hamper compliance in regions like Africa, even when people are willing to abide by these rules. For the same reasons, African countries might also be unable to implement WHO's recommended quarantine strategies at airports and hospitals for suspected contact tracing of confirmed cases. ${ }^{9}$ The possibility of an outbreak of other infectious causes, including an Ebola outbreak, on top of COVID-19, may add further complexity to the already complex public health systems in the region. ${ }^{10}$

Cognisant of the multifaced effects of the pandemic and the need for better preparation, the Africa Centres for Disease Control and Prevention has established a task force in six main work streams: laboratory diagnosis; surveillance, including screening at points of entry and cross-border activities; infection prevention and controlling healthcare facilities; clinical treatment of people with severe COVID-19; risk communication; and supply chain management and stockpiles. ${ }^{11}{ }^{12}$ Public health and social measures have also been implemented across Africa which included, but not limited to, shutting borders, introducing self-isolation of exposed persons and establishing of quarantine centres. ${ }^{5}$ However, adherence to prevention measures varied remarkably. ${ }^{13-15}$

The few available studies showed that while there was limited surge capacity to provide COVID-19 treatment, the pandemic also affected the general public's access to essential health services. ${ }^{16}{ }^{17}$ While there were two scoping reviews to date, one investigated the impact of COVID-19 on maternal and perinatal health, ${ }^{18}$ and the other focused on access to sexual and reproductive health, ${ }^{19}$ both reviews were based on experience from western countries. It is worth reviewing the available evidence on the level of health system preparedness, impacts of and responses for COVID-19 in Africa, which is the aim of this scoping review.

\section{METHODS}

\section{Study design}

We conducted a scoping review since it allows us to capture the broad nature of the research question and range of health system preparedness measures, impacts of and responses implemented across Africa in different settings. We followed the methodological framework suggested by Arksey and $\mathrm{O}^{\prime}$ Malley ${ }^{20}$ and further refined by Levac et $a l^{21}$ which comprised of the following five steps: (a) identifying research questions, (b) identifying relevant studies, (c) selection of studies, (d) extraction and charting of data and (e) summarising and reporting results.

\section{Identifying research questions}

The following questions guided the scoping review: (1) How well prepared were the existing health systems in responding to adverse impacts of COVID-19 infection? (2) What were the implications or consequences associated with COVID-19 on the healthcare system in Africa? (3) How did the health system respond in maintaining pre-pandemic health service needs, including providing essential healthcare services?

To effectively answer these questions, we adopted the population, concept and context framework developed by the Joanna Briggs Institute, ${ }^{22}$ as described in table 1 .

\section{Identifying relevant studies}

GAT developed a comprehensive searching strategy and discussed with the research team, presented in online supplemental file 1 . We searched peer-reviewed papers on PubMed, Scopus and CINAHL bibliographic databases for peer-reviewed articles. Since grey literature such as unpublished work, preprint articles and relevant government reports on COVID-19 have grown in number and significance, we also searched Google and Google Scholar and MedRxiv and Research Square websites. We considered studies that employed quantitative or qualitative methods and reported health systems more broadly or any essential health services. These studies reported the impact of COVID-19 on maternal and child health services, services for infectious diseases such as tuberculosis, malaria, HIV and antiretroviral treatment services, chronic care, cancer care, hypertension care and treatment, and mental health services. We included studies conducted between 1 December 2019 and 21 March 2021, at which time the comprehensive literature search was performed.

\section{Study selection}

We included any published, preprint or grey literature in English that explored a combination of the following 


\begin{tabular}{|c|c|c|}
\hline Criteria & Element(s) & Descriptions \\
\hline \multirow{2}{*}{$\begin{array}{l}\text { P- } \\
\text { Population }\end{array}$} & All people & All individuals accessing healthcare services. \\
\hline & $\begin{array}{l}\text { Health } \\
\text { workforce }\end{array}$ & $\begin{array}{l}\text { Healthcare workers such as physicians, nurses, midwives and paramedics working as frontline contact in the } \\
\text { healthcare system. }\end{array}$ \\
\hline \multirow[t]{3}{*}{$\begin{array}{l}\text { C- } \\
\text { Concept }\end{array}$} & Preparedness & $\begin{array}{l}\text { The ability and readiness of the health system to avail material and human resources to provide general and } \\
\text { essential services during the pandemic. }\end{array}$ \\
\hline & Impact & The effects that COVID-19 has on the provision of uptake and access to health services. \\
\hline & Response & $\begin{array}{l}\text { The capacity of the health systems to mobilise the required resources and act quickly to address the adverse } \\
\text { consequences of COVID-19 pandemic; deliver all the necessary health services to those in need and support } \\
\text { the healthcare workers during the pandemic. }\end{array}$ \\
\hline \multirow[t]{3}{*}{ C-Context } & $\begin{array}{l}\text { General health } \\
\text { services }\end{array}$ & $\begin{array}{l}\text { Any health service sought by patients at any level-community health posts, health centres, hospitals-or } \\
\text { provider-public or private-settings. }\end{array}$ \\
\hline & $\begin{array}{l}\text { Essential health } \\
\text { services }\end{array}$ & $\begin{array}{l}\text { Healthcare services comprising any of the following services: maternal and child health services such as } \\
\text { antenatal care, facility delivery, postnatal care and immunisation services; infectious diseases such as malaria, } \\
\text { HIV and chronic care including cancer treatment. }\end{array}$ \\
\hline & $\begin{array}{l}\text { African } \\
\text { countries }\end{array}$ & $\begin{array}{l}\text { Any country in continental Africa that reported on preparedness, impacts and responses of COVID-19 on } \\
\text { general or essential health services and its health workforce. }\end{array}$ \\
\hline
\end{tabular}

three terms: 'health system preparedness', 'the impact of' and 'responses for COVID-19 pandemic by the healthcare system'. Two investigators (GAT and FHT) searched and screened the studies by titles and abstracts and then reviewed the full texts of potential studies. Records were managed by EndNote X9.0 software. The reference lists of the included studies were screened for relevant studies. Any questions around study eligibility were resolved through consensus between the two investigators (GAT and FHT). However, we excluded articles that mainly focused on the clinical and biological conditions of the diseases without any contextual linkage into the health system or those investigating the perceived/anticipated health system impact of the COVID-19 pandemic. Editorials, commentaries and letters to the editor that did not involve primary data were also excluded.

\section{Data charting process}

Two reviewers (GAT and FHT) initially developed a pre-determined electronic data-charting form that the research team later discussed and agreed on. Five reviewers (GAT, BAD, AGT, KG, DE) extracted data from included studies. The data extraction form had the year of publication, country name, article title, journal, study design, study setting and population. It also captured the key findings reported in the three core areas of health systems (ie, preparedness, impact and response) and limitations acknowledged in each study.

\section{Summarising and reporting the results}

We used a thematic content analysis using narrative descriptions of the extracted data, and organised the results under three main domains: preparedness, impacts and responses. We reported the review following the Preferred Reporting Items for Systematic Reviews and Meta-Analyses guidelines Extension for Scoping Review reporting standards (online supplemental file 2). ${ }^{23}$

\section{Patient and public involvement}

The study did not involve patients or the general public. Their input was not sought in the systematic review design, interpretation of results, or drafting or editing this document.

\section{Ethics statement}

This study was a systematic review of publically avilable literature, and ethical approval was not required.

\section{RESULTS \\ Description of studies}

We retrieved 804 records from databases and an additional 37 documents from grey literature sources. After removing duplicates, 747 records remained for titles and abstracts screening, of which 83 articles were retrieved for full-text screening. We conducted the final review on 22 studies, ${ }^{1624-44}$ of which $19(86.4 \%)$ were quantitative (figure 1, table 2). A total of 61 papers were excluded for the following reasons: studies assessed clinical and biomedical aspects of COVID-19 ( $\mathrm{n}=28)$; covered expert opinions or commentary that did not involve primary data $(n=12)$; assessed perceived or anticipated impacts $(n=13)$; were not focused on Africa $(n=8)$.

\section{Characteristics of the included studies}

Table 2 summarises the key characteristics of the studies included in our review. Of the included studies, about three-quarters $(72.7 \%$ ) were published in 2020. Except for four studies ${ }^{2431} 3842$ that were multicountry, 18 came from 10 different countries: four were from Ethiopia, ${ }^{16} 323336$ three each from Kenya, ${ }^{27} 3443$ and Uganda. ${ }^{28}{ }^{3041}$ While $18(81.8 \%)$ were original studies ${ }^{16} 24$ 26-30 32-35 $37384042-44$ published either in peer-reviewed journals or available in preprint repositories, the remaining four studies ${ }^{25} 313639$ were published as letters to editors or commentaries but 


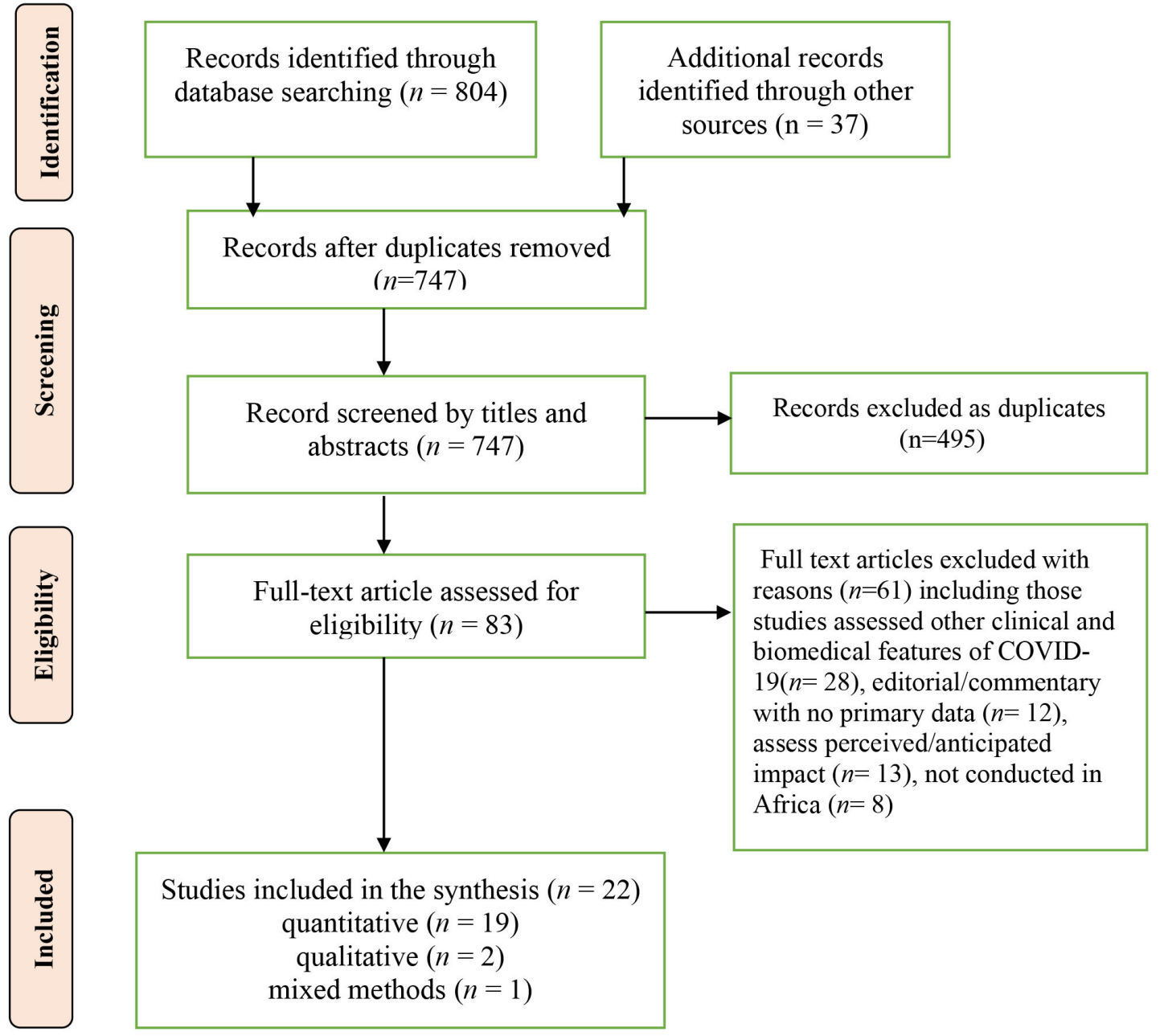

Figure 1 PRISMA-ScR flow diagram.

backed up by primary data. Of the included studies, 19 studies $^{16} 24 \quad 25$ 28-32 34-41 43-45 described the impacts of COVID-19 on accessing healthcare services, 7 studies $^{24-283338}$ reported health system responses to mitigate COVID-19 and 6 studies ${ }^{242627323338}$ provided information on health system preparedness. Six studies $2426-283438$ focused on the general healthcare system. At the same time, four studies investigated specific health services components such as essential healthcare services, including specific healthcare delivery for maternal, child and sexual and reproductive health services. ${ }^{29} 303543$ Additionally, three studies focused on infectious diseases such as tuberculosis ${ }^{3637}$ and HIV. ${ }^{39}$ Another three studies reported on healthcare services for cancer care ${ }^{25}$ mental health services ${ }^{40}$ and integrated care for hypertension and HIV. ${ }^{41}$ Moreover, four studies ${ }^{31-33} 42$ assessed health workforce preparedness and workers' experiences during the pandemic. Details of the study characteristics are provided in online supplemental file 3 .

\section{Main themes from the included study}

Health system preparedness

Six studies 262732333842 included under this theme demonstrated a low level of preparedness of Africa's health system to prevent, diagnose and manage the COVID-19 pandemic in the region (table 3 , online supplemental file 4).

Resources to manage and guide COVID-19 were limited or not available

Three studies ${ }^{26} 3342$ reported insufficient resources, including personal protective equipment (PPE) and clinical guidelines for healthcare providers during the pandemic. A Tanzanian study ${ }^{26}$ showed low health facility readiness for COVID-19 prevention measures, with only two-thirds $(64 \%)$ of urban and one-third of rural $(32.9 \%)$ health facilities having functioning communication systems. A study from Ethiopia showed that half $(50 \%)$ of the healthcare providers were not satisfied with the available medical equipment for COVID-19 treatment in their hospitals. ${ }^{33}$ A global study that included African countries also reported that over half (53\%) of healthcare workers working in maternal and neonatal health service provisions in low/middle-income countries did not receive updated guidelines for the management of COVID-19. ${ }^{42}$

Healthcare workers preparedness

Two studies ${ }^{3342}$ assessed the knowledge of healthcare workers on different aspects of COVID-19 and showed 
Table 2 Summary of studies by study context and main focus in the healthcare system

Characteristics Number (\%) Evidence

Publication year

2020

$16(72.3)$

Abdela et al, ${ }^{16}$ Ahmed et al, ${ }^{24}$ Ammor et al,,$^{25}$ Bajaria et al, ${ }^{26}$ Barasa et al,,${ }^{27}$ Bell et al, ${ }^{28}$

Buonsenso et al, ${ }^{29}$ Gichuna et al, ${ }^{34}$ Mohammed et al, ${ }^{36}$ Odume et al, ${ }^{37}$ Sagaon-Teyssie et al, ${ }^{40}$ Jensen et al, ${ }^{35}$ Pierre et al, ${ }^{39}$ Semaan et al, ${ }^{42}$ Shikuku et al, ${ }^{43}$ Siedner et al ${ }^{44}$

2021

$6(27.3)$

Burt et al, ${ }^{30}$ Deressa et al,,$^{32}$ Desalegn et al, ${ }^{33}$ Otitoloju et al, ${ }^{38}$ Schwartz et al, ${ }^{41}$ Debes et al ${ }^{31}$

Country of study

\begin{tabular}{|c|c|c|}
\hline Ethiopia & $4(18.2)$ & Abdela et $a l,{ }^{16}$ Deressa et $a l,{ }^{32}$ Desalegn et $a l,{ }^{33}$ Mohammed et $a l^{36}$ \\
\hline Kenya & $3(13.6)$ & Barasa et $a l,{ }^{27}$ Gichuna et al,${ }^{34}$ Shikuku et al ${ }^{43}$ \\
\hline Nigeria & $1(4.5)$ & Odume et $a l^{37}$ \\
\hline Uganda & $3(13.6)$ & Bell et $a l,{ }^{28}$ Burt et $a l,{ }^{30}$ Schwartz et al ${ }^{41}$ \\
\hline Rwanda & $1(4.5)$ & Pierre et $a l^{39}$ \\
\hline Tanzania & $1(4.5)$ & Bajaria and $\mathrm{Abdul}^{26}$ \\
\hline Mali & $1(4.5)$ & Sagaon-Teyssie et $\left.a\right|^{40}$ \\
\hline Morocco & $1(4.5)$ & Ammor et $a l^{25}$ \\
\hline Sierra Leone & $1(4.5)$ & Buonsenso et $a l^{29}$ \\
\hline South Africa & $2(9.1)$ & Jensen and McKerrow, ${ }^{35}$ Siedner et al ${ }^{44}$ \\
\hline Multicountry* & $4(18.2)$ & Ahmed et $a l,{ }^{24}$ Debes et $a l,{ }^{31}$ Otitoloju et $a l,{ }^{38}$ Semaan et al ${ }^{42}$ \\
\hline
\end{tabular}

Types of articles

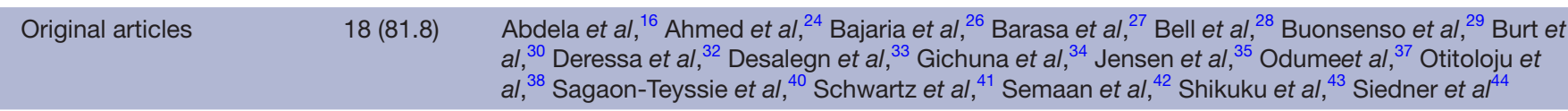

Commentary/letter to

editor†

4 (18.2)

Pierre et al, ${ }^{39}$ Mohammed et $a l,{ }^{36}$ Debes et al, ${ }^{31}$ Ammor et $a l^{25}$

Study designs

Quantitative

$19(86.4)$

Abdela et al,$^{16}$ Ammor et al, ${ }^{25}$ Bajaria et al, ${ }^{26}$ Barasa et al, ${ }^{27}$ Bell et al, ${ }^{28}$ Buonsenso et al, ${ }^{29}$ Burt et al, ${ }^{30}$ Debes et al, ${ }^{31}$ Deressa et al, ${ }^{32}$ Desalegn et al, ${ }^{33}$ Jensen and McKerrow, ${ }^{35}$ Mohammed et $a l,{ }^{36}$ Odume et al, ${ }^{37}$ Otitoloju et al, ${ }^{38}$ Pierre et al, ${ }^{39}$ Sagaon-Teyssieet al, ${ }^{40}$ Schwartz et al, ${ }^{41}$ Shikuku et al, ${ }^{43}$ Siedner et al ${ }^{44}$

\begin{tabular}{|c|c|c|}
\hline Qualitative & $2(9.1)$ & Ahmed et $a l,{ }^{24}$ Gichuna et $a l^{34}$ \\
\hline Mixed methods research & $1(4.5)$ & Semaan et $a l^{42}$ \\
\hline \multicolumn{3}{|l|}{ Health services context } \\
\hline $\begin{array}{l}\text { General health services/ } \\
\text { health system }\end{array}$ & $6(27.3)$ & Ahmed et $a l,{ }^{24}$ Gichuna et al, ${ }^{34}$ Abdul, $^{26}$ Barasa et al, ${ }^{27}$ Bell et $a l,{ }^{28}$ Otitoloju et a ${ }^{38}$ \\
\hline $\begin{array}{l}\text { Essential healthcare service } \\
\text { delivery }\end{array}$ & $2(9.1)$ & Abdela et $a l,{ }^{16}$ Siedner et $a l^{44}$ \\
\hline $\begin{array}{l}\text { Maternal, child, sexual } \\
\text { and reproductive health } \\
\text { services }\end{array}$ & $4(18.2)$ & Burt et $a l,{ }^{30}$ Jensen and McKerrow, ${ }^{35}$ Shikuku et al, ${ }^{43}$ Buonsenso et al ${ }^{29}$ \\
\hline Infectious diseasesł & $3(13.6)$ & Mohammed et al, ${ }^{36}$ Odume et $a l,{ }^{37}$ Pierre et al ${ }^{39}$ \\
\hline Chronic care§ & $3(13.6)$ & Ammor et al, ${ }^{25}$ Sagaon-Teyssie et al, ${ }^{40}$ Schwartz et al ${ }^{41}$ \\
\hline Health workforce & $4(18.2)$ & Debes et $a l,{ }^{31}$ Desalegn et al, ${ }^{33}$ Semaan et al, ${ }^{42}$ Deressa et $a l^{32}$ \\
\hline \multicolumn{3}{|l|}{ Main focus } \\
\hline Preparedness & $6(22.7)$ & $\begin{array}{l}\text { Ahmed et } a l,{ }^{24} \text { Bajaria and Abdul, }{ }^{26} \text { Barasa et al },{ }^{27} \text { Desalegn et } a l,{ }^{33} \text { Deressa et al },{ }^{32} \text { Otitoloju et } \\
l^{88}\end{array}$ \\
\hline Impact & $19(86.4)$ & $\begin{array}{l}\text { Abdela et al, }{ }^{16} \text { Ahmed et al, }{ }^{24} \text { Ammor et al, }{ }^{25} \text { Bell et al, }{ }^{28} \text { Buonsenso et al, }{ }^{29} \text { Burt et al, }{ }^{30} \text { Debes } \\
\text { et al, }{ }^{31} \text { Deressa et } a l,{ }^{32} \text { Desalegn et al }{ }^{34} \text { Gichuna et al, }{ }^{34} \text { Jensen and McKerrow }{ }^{35} \text { Mohammed } \\
\text { et al, }{ }^{36} \text { Odume et al }{ }^{37} \text { Otitoloju, et al, }{ }^{38} \text { Pierre et al },{ }^{39} \text { Sagaon-Teyssie et al }{ }^{40} \text { Schwartz et al, }{ }^{41} \\
\text { Shikuku et al, }{ }^{43} \text { Siedner et al, }{ }^{44} \text { Semaan et al }{ }^{42}\end{array}$ \\
\hline Response & $7(31.8)$ & Ahmed, et al, ${ }^{24}$ Ammor et $a l,{ }^{25}$ Barasa et $a l,{ }^{27}$ Bell et al, ${ }^{28}$ Otitoloju, et al,,$^{38}$ Semaan et al ${ }^{42}$ \\
\hline
\end{tabular}

*Studies involving one or more African counties as part of a global study.

†Included letters to editor's papers that was conducted based on a primary study.

$\ddagger$ Tuberculosis and HIV care services.

$\S$ Cancer, mental health, integrated care for hypertension and HIV.

ףMore than one aspect was involved. 
Table 3 Summary of key findings on preparedness, impact and response of heathcare system in included studies

\begin{tabular}{|c|c|c|}
\hline Health system context & Evidence & Examples \\
\hline \multicolumn{3}{|l|}{ Preparedness } \\
\hline \multirow[t]{2}{*}{$\begin{array}{l}\text { Resources to prevent } \\
\text { COVID-19 were limited or } \\
\text { not available }\end{array}$} & $\begin{array}{l}\text { Bajaria and } \\
\text { Abdul }^{26}\end{array}$ & $\begin{array}{l}\text { Limited availability of some COVID-19 precaution products, such as medical masks, } \\
\text { disinfectants, alcohol-based hand rub and access to running water, especially at publicly } \\
\text { managed facilities and facilities in rural areas. }\end{array}$ \\
\hline & Semaan et $a l^{42}$ & $\begin{array}{l}\text { Less than half }(47 \%) \text { of respondents in LMICs received updated guidelines for care } \\
\text { provision. }\end{array}$ \\
\hline $\begin{array}{l}\text { Knowledge gaps by } \\
\text { healthcare workers }\end{array}$ & $\begin{array}{l}\text { Desalegn et } \\
a^{33}\end{array}$ & $\begin{array}{l}\text { Moderate knowledge about signs and symptoms, identification of persons at risk } \\
\text { of developing the disease, case definition of COVID-19, appropriate tests offered to } \\
\text { suspected cases and high-risk patients and preventive measures that help to minimise the } \\
\text { risk of transmission. }\end{array}$ \\
\hline
\end{tabular}

Limited surge capacity and Barasa et $a l^{27}$ low testing ability
- Limited ICU bed surge capacity.

-When equipment were available, they were not functioning properly.

-While Kenya has 537 ICU beds, it only has 256 ventilators.

Otitoloju et $\mathrm{a}^{38}$ The testing capacity in African countries was very low. Most of the countries on the very low capacity need to scale up rapidly.

Limited or no available health services needed during the pandemic

\section{Impact}

Reduced patient flow or limited access to health services
Ahmed, et $a^{24}$

Mental health services and those addressing gender-based violence were perceived to be limited or unavailable. tuberculosis).
Abdela et $a l^{16}$

Ahmed et $\left.a\right|^{24}$

Ammor et $a l^{25}$

Bell et $\left.a\right|^{28}$

Burt et $\left.a\right|^{30}$

Buonsenso et $a^{29}$

Gichuna et $a l^{34}$

Jensen and

McKerrow $^{35}$
Reduced patient flow for accessing essential health services (maternal and child health and

Stakeholders perceive a reduction in access to all healthcare services in slums during COVID-19 lockdowns with services uptake was affected by an increased cost of healthcare, reduced household income, increased challenges in physically reaching healthcare facilities and exacerbated reluctance of residents to seek healthcare due to fear of infection and stigmatisation.

- A significant decrease in patients' admissions during the lockdown period at the different units of oncologic centre.

Reduction in the rate of detection of HIV and malaria and reduction of the provision of prophylaxis for tuberculosis prevention for patients with HIV.

- Reduction in facility deliveries is March 2020.

- Reduced attendance for antenatal care services, neonatal admission and prevention of mother to child transmission of HIV remarkably.

- The under-five vaccination rate dropped by $50 \%-80 \%$ in 2020 compared with the previous year $(p<0.0005)$.

mited access to receive sexual and reproductive healthcare services by female sex workers.

- Limited access to some reproductive health commodities. 'One of the main commodities we lack is family planning. During this time if we are not careful we will deliver a lot of 'corona babies'. There is a problem with Norplant and the family planning injectables are also not available for continuing women. This is not good for us. (Sex Worker, 40 years, Kasarani)'

- Significant declines for clinic attendance (36\%; $p=0.001)$ and hospital admissions $(50 \%$; $\mathrm{p}=0.005$ ) of children aged $<5$ years and a $47 \%$ increase in neonatal facility deaths were reported. 
Table 3 Continued

\begin{tabular}{|c|c|c|}
\hline \multirow[t]{4}{*}{ Health system context } & Evidence & Examples \\
\hline & $\begin{array}{l}\text { Mohammed } \\
\text { et } a l^{36}\end{array}$ & The pandemic has reduced TB care significantly including diagnosis, care and treatment. \\
\hline & Odume et $\left.a\right|^{37}$ & $\begin{array}{l}\text { TB clinic attendance, presumptive TB identification, TB cases detection and treatment } \\
\text { initiation significantly decreased since the onset of the COVID-19 }(p<0.001) \text {. }\end{array}$ \\
\hline & Siedner et $a l^{44}$ & $\begin{array}{l}\text { There was a }>50 \% \text { reduction in child healthcare visits at the start of the level five lockdown } \\
\text { from } 11.9 \text { to } 4.7 \text { visits/day ( } 7.1 \text { visits/clinic/day, } 95 \% \mathrm{Cl}=8.9 \text { to } 5.3) \text {, both for children aged } \\
<1 \text { year and } 1-5 \text { years. }\end{array}$ \\
\hline \multirow[t]{3}{*}{$\begin{array}{l}\text { Missed appointment for } \\
\text { chronic care services }\end{array}$} & Pierre et $a l^{39}$ & $\begin{array}{l}\text { Less than half ( } 48 \%) \text { patients with HIV attended scheduled antiretroviral treatment } \\
\text { collection clinic appointments. }\end{array}$ \\
\hline & Gichuna et $a l^{34}$ & $\begin{array}{l}\text { Female sex worker reported a missed appointment due to COVID-19 restrictions to travel: } \\
\text { 'I have missed my appointments to the clinic at BHESP (Bar Hostess Empowerment and } \\
\text { Support Program). I was supposed to go collect my ARVs but now with the lockdown, } \\
\text { how will I go to collect them? I cannot visit the public health facility because of stigma and } \\
\text { discrimination. (Sex worker, } 21 \text { years, Jogoo Road)' }\end{array}$ \\
\hline & $\begin{array}{l}\text { Schwartz et } \\
a l^{41}\end{array}$ & $\begin{array}{l}\text { Compared with the pre-lockdown period }(0.4 \%-5.2 \%) \text {, the percentage of missed } \\
\text { appointments during lockdown for HIV and hypertension care ranged from } 16.2 \% \text { to } \\
21.5 \% \text {. }\end{array}$ \\
\hline \multirow[t]{2}{*}{$\begin{array}{l}\text { Re-orientation of services } \\
\text { deter essential services } \\
\text { provision }\end{array}$} & $\begin{array}{l}\text { Mohammed } \\
\text { et } a l^{36}\end{array}$ & $\begin{array}{l}\text { Human and material resources for tuberculosis have been shifted to COVID- } 19 \text {. } \\
\text { Some health facilities that have been providing tuberculosis care and treatment services } \\
\text { have been committed as COVID-19 isolation and treatment centres. }\end{array}$ \\
\hline & Gichuna et $a l^{34}$ & $\begin{array}{l}\text { It was observed disruption of supply for reproductive health commodities due to the focus } \\
\text { on COVID-19 had led to a neglect of routine reproductive healthcare services especially } \\
\text { in the public health centres. 'For now, when you visit the public health facility, we cannot } \\
\text { be given contraception, priority has been given to responding and attending to emergency } \\
\text { cases. (Sex workers, } 20 \text { years, Jogoo Road)' }\end{array}$ \\
\hline \multirow{5}{*}{$\begin{array}{l}\text { Not all services were } \\
\text { affected }\end{array}$} & Abdela et $a 1^{16}$ & Attendance for health facility delivery services was stable during the pandemic). \\
\hline & Siedner et $a l^{44}$ & $\begin{array}{l}\text { There was no drop-in clinic visitation in adults at the start of the Level } 5 \text { lockdown, or } \\
\text { related to HIV care. }\end{array}$ \\
\hline & $\begin{array}{l}\text { Schwartz et } \\
a l^{41}\end{array}$ & $\begin{array}{l}\text { During the lockdown, } 49 \%-66 \% \text { of those who missed appointments for HIV care sought } \\
\text { care at other health facilities but not for hypertension due to its limited integration. }\end{array}$ \\
\hline & Shikuku et a/ ${ }^{43}$ & $\begin{array}{l}\text { No differences in monthly mean }( \pm S D) \text { attendance between March and June } 2019 \text { vs } 2020 \\
\text { for antenatal care, hospital births, family planning attendance, post-abortion care and } \\
\text { pentavalent } 1 \text { immunisation. }\end{array}$ \\
\hline & Burt et $\left.a\right|^{30}$ & $\begin{array}{l}\text { Immediate postnatal care, and contraceptive provision remained stable during the } \\
\text { pandemic. }\end{array}$ \\
\hline
\end{tabular}

Impact on healthcare providers

\begin{tabular}{|c|c|c|}
\hline Perceived stigma & Debes et $\left.a\right|^{31}$ & $\begin{array}{l}\text { Over half }(56 \%) \text { of health professionals reported safety concerns related to stigma from } \\
\text { being healthcare workers. }\end{array}$ \\
\hline \multirow[t]{3}{*}{$\begin{array}{l}\text { Experienced mental health } \\
\text { illness }\end{array}$} & $\begin{array}{l}\text { Sagaon- } \\
\text { Teyssie et } a l^{40}\end{array}$ & $\begin{array}{l}72 \%, 73 \% \text { and } 77 \% \text { of participants (community healthcare providers) reported depression, } \\
\text { anxiety and insomnia symptoms, respectively. }\end{array}$ \\
\hline & Semaan et $a l^{42}$ & $\begin{array}{l}\text { Healthcare workers providing essential services to women and newborns during } \\
\text { this pandemic experience increased stress and anxiety levels. An obstetrician from } \\
\text { Mozambique described, 'My stress level is immeasurable. Every time a pregnant woman } \\
\text { with flu-like symptoms (visits the health facility), I feel almost completely lost. I need to be } \\
\text { equally protected and I don't feel any protection from whoever (is responsible for protecting } \\
\text { me)'. }\end{array}$ \\
\hline & Deressa et $\left.a\right|^{32}$ & $\begin{array}{l}\text { About } 38 \% \text { of respondents were perceived as somewhat worried and a half ( } 50 \%) \text { were } \\
\text { apprehensive due to the potential risk of becoming infected with COVID-19 by their clinical } \\
\text { role in the hospital setting. } \\
\text { About two-thirds ( } 65 \%) \text { were extremely worried about the potential risk of infection to their } \\
\text { family and loved ones. }\end{array}$ \\
\hline \multicolumn{3}{|l|}{ Response } \\
\hline \multirow[t]{2}{*}{ Provision of guidelines } & Otitoloju et $\left.a\right|^{38}$ & $\begin{array}{l}\text { Countries adopted the WHO protocols, personal hygiene, economic palliatives and social } \\
\text { distancing measures. }\end{array}$ \\
\hline & Semaan et $a l^{42}$ & $\begin{array}{l}\text { Lack of national guidelines to facilitate the provision of health services for pregnant women. } \\
\text { An obstetrician/gynaecologist from Uganda expressed: 'I am worried that no national } \\
\text { guidelines (are) rolled out yet regarding care for pregnant women and newborns.' }\end{array}$ \\
\hline
\end{tabular}


Table 3 Continued

\begin{tabular}{|c|c|c|}
\hline Health system context & Evidence & Examples \\
\hline \multirow[t]{2}{*}{$\begin{array}{l}\text { Tailored healthcare } \\
\text { services and consultation }\end{array}$} & Ahmed et $a l^{24}$ & $\begin{array}{l}\text { Mobile consultation using phones at the time of pandemic lockdowns. A Kenyan health } \\
\text { manager expressed: 'We have given out telephone numbers for the rapid response team } \\
\text { to help with COVID-related cases. We also have a health facility telephone numbers for } \\
\text { patients to call and talk to a health worker for non-communicable conditions that need } \\
\text { monitoring. That way we can continue providing other services besides COVID-19 and } \\
\text { ensure continuity of services.' }\end{array}$ \\
\hline & & - Increased patronage of locally available services. \\
\hline $\begin{array}{l}\text { Implementing COVID-19 } \\
\text { prevention methods } \\
\text { to avoid COVID-19 } \\
\text { transmission inside the } \\
\text { facility }\end{array}$ & Ammor et $a l^{25}$ & $\begin{array}{l}\text { Surgical masks were provided for non-suspected patients. } \\
\text { Suspected patients with COVID-19 were isolated in a dedicated area, and later referred to } \\
\text { COVID-19 facilities for further examinations. }\end{array}$ \\
\hline
\end{tabular}

ARV, antiretroviral drugs; $\mathrm{Cl}$, confidence interval; HIV, human immunodeficiency virus; ICU, intensive care unit; LMICs, low and middle-income countries; WHO, World Health Organization.

mixed findings. The study from Ethiopia showed that healthcare workers generally had moderate knowledge on detection and management of COVID-19. ${ }^{33}$ Another study showed limited understanding of case definition, identification of high-risk patients, tests appropriate to identify suspected cases and lack of adequate preventive measures to minimise transmission. ${ }^{42}$ In this study, only $15 \%$ of the participants perceived that they had complete knowledge to provide maternity care to patients with COVID-19. ${ }^{42}$ The same study also reported on the lack of training opportunities for staff and shortage of qualified staff as some experienced staff were not on their role partly due to self-isolation because of contact with patients with COVID-19 infection. ${ }^{42}$

\section{Limited surge capacity and low testing ability}

A study in Kenya ${ }^{27}$ showed that health facilities had limited surge capacity due to a lack of ICU beds and ventilators. Even when these equipment were available, there were also concerns about the lack of accompanying equipment or managing the equipment properly. Studies also noted resource gaps, particularly the incompatibility between infection rates and the infrastructure available to provide COVID-19 testing, given the size of the population in the region. For example, Otitoloju et $a l^{88}$ reported that while few countries such as Mauritius, Ghana, South Africa, Botswana, Tunisia and Cape Verde had a medium to higher ability to carry out COVID-19 testing, the capacity in most African countries was low compared with their population size.

\section{Lack of essential services needed during the pandemic}

Despite the anticipated increase in demand for some health services, such as mental health, following a pandemic, including COVID-19, the review identified no concomitant expansion in health services to address mental health issues or gender-based violence in some countries. ${ }^{24}$

\section{Impact of COVID-19 on health services utilisation}

The included studies reported a range of impacts associated with the emergence of the COVID-19 pandemic in one or more African countries (table 3, online supplemental file 4).

Reduced patient flow or limited access to health services Over half of the studies ${ }^{1624} 2528-3034-3744$ showed significant reductions in inpatient hospital admissions and access to essential and general health services. The COVID-19-related lockdown restrictions has impacted all healthcare services ${ }^{24}$ including HIV care, treatment for malaria and tuberculosis, and maternal and child health services. ${ }^{25} 35$ A study from Ethiopia reported a decline in service utilisation as high as $98 \%$ for family planning services and up to $50 \%$ for antenatal care attendance compared with pre-pandemic trends. ${ }^{16}$ In addition, three studies ${ }^{1636} 37$ have observed substantial declines in diagnosis and management of tuberculosis services. As a study from Ethiopia revealed, part of the decline was attributed to the re-orientation of health services as some healthcare facilities have been re-purposed to serve for COVID-19 care services. ${ }^{36}$ Similarly, in Kenya, routine reproductive healthcare services were neglected due to priorities accorded to COVID-19-related services, especially in the public health centres. ${ }^{34} \mathrm{~A}$ female sex worker expressed her concern as: 'For now, when you visit the public health facility, we cannot be given contraception; priority has been given to responding and attending to emergency cases. (Sex workers, 20 years, Jogoo Road)' (p. 1436) ${ }^{34}$ In South Africa, there was a $36 \%-50 \%$ reduction in the rate of child healthcare visits ${ }^{3544}$ and a $50 \%$ decline in hospitalisations for child health services. ${ }^{35}$ Other essential health services with a reduced patient flow included prevention of mother to child transmission of HIV ${ }^{30}$ malaria diagnosis and treatment services, ${ }^{28}$ sexual and reproductive healthcare services for some segments of the population such as female sex workers, ${ }^{34}$ and patient admissions for 
oncologic services. ${ }^{25}$ Moreover, under-five vaccination rates in the region have declined significantly, by up to $50 \%-80 \%$, in the post-pandemic period as compared with the year immediately before the pandemic. ${ }^{29}$

\section{Missed appointments for chronic care services}

Three studies reported that COVID-19 impacted certain health services in chronic care follow-up clinics as patients could not attend routine appointments for follow-up and refilling drugs. ${ }^{34941}$ A study in Rwanda showed that over half of patients with HIV with scheduled appointments were not visiting antiretroviral treatment collection clinics during COVID-19 lockdown, with patients from outside Kigali and patients with advanced HIV status (WHO stages 3 and 4) were impacted more than their counterparts. ${ }^{39}$ Similarly, a Kenyan study showed that female sex workers could not attend their appointments due to the pandemic, as expressed by a female sex worker: 'I have missed my appointments to the clinic at BHESP [Bar Hostess Empowerment and Support Program]. I was supposed to go and collect my ARVs, but now, how will I collect them with the lockdown? I cannot visit the public health facility because of stigma and discrimination. (Sex worker, 21 years, Jogoo Road)' (p.1434). ${ }^{34}$

\section{Access to some health services in some settings was stable} Five studies ${ }^{16} 30414344$ reported that COVID-19 did not hamper health services provisions or affect the number of patients attending health services during the pandemic. For example, a Kenyan study comparing the monthly rate of antenatal care, hospital skilled births, family planning, post-abortion care and immunisation services during the 4 months before (March-June 2019) and after the COVID-19 pandemic (July-September 2019) showed no difference. Similarly, a study conducted in Uganda showed that, unlike other essential health services, immediate postnatal care and contraceptive provision remained stable during the pandemic. ${ }^{30}$ A study in Ethiopia showed that while family planning services were severely affected by the pandemic, the effects were minimal for institutional delivery services. ${ }^{16}$ Similarly, a study from Uganda showed that despite COVID-19-related national lockdown, HIV services were still available in the country during the early phase of the pandemic, though this was not the case for hypertension services, reflecting the lag in integrated service delivery for chronic conditions. ${ }^{41}$

\section{Impact of COVID-19 on healthcare workers}

Four studies ${ }^{31} 324042$ showed that healthcare workers had experienced mental health issues due to stressful working conditions and perceived fear of acquiring COVID-19 infection. For example, a study conducted in Mali involving community healthcare workers showed that about three-quarters $(72 \%-77 \%)$ of the participants reported having at least one of the three symptoms of mental illness, including depression, anxiety and insomnia. ${ }^{40}$ Similarly, an obstetrician from Mozambique who participated in a global study described their circumstances as follows: 'My stress level is immeasurable. Every time a pregnant woman with flu-like symptoms (visits the health facility), I feel almost completely lost. I need to be equally protected, and I don't feel any protection from whoever (is responsible for protecting me)' $(\mathrm{p}$. 6). ${ }^{42}$ While about $38 \%-50 \%$ of healthcare workers reported somewhat to extremely worried for themselves being at risk of COVID-19 infections. Nearly two-thirds $(65 \%)$ were extremely worried that they could potentially risk their families and loved ones for COVID-19 as they continued to be in hospital settings for clinical duty. ${ }^{32}$ Similarly, a survey of healthcare providers from 13 African countries demonstrated an increase in daily depression for stigmatisation in their community. ${ }^{31}$

\section{Health system responses}

Three studies ${ }^{2425} 38$ reported on responses taken by the healthcare system to prevent the negative consequences of the COVID-19 pandemic and maintain existing health services provision. Table 3 summarises the findings from these studies, while the details are provided in online supplemental file 4 .

\section{Provision of guidelines}

The results related to guidelines provisions and adoptions are mixed. A preliminary evaluation of COVID-19 outcomes throughout African countries showed that almost all countries adopted the WHO protocol and guidance. Most countries established compulsory isolation and treatment centres for treating COVID-19 positive patients, mainly with hydroxychloroquine, chloroquine and chloroquine-azithromycin combination. ${ }^{38}$ However, interviews with healthcare workers from Uganda demonstrated a lack of national guidelines to facilitate the provision of health services for pregnant women. 'I am worried that no national guidelines (are) rolled out yet regarding care for pregnant women and newborns', an obstetrician/gynaecologist had remarked.(p. 4$)^{42}$

\section{Establish a channel for consultation}

A multicountry study that examined response mechanisms during the early phase of the pandemic ${ }^{24}$ had demonstrated the use of telephone consultation to mitigate the challenges of physically accessing health facilities by patients. A healthcare worker in Kenya attested that: "We have given out telephone numbers for the rapid response team to help with COVID-related cases. We also have a health facility telephone number for patients to call and talk to a health worker for non-communicable conditions that need monitoring. That way, we can continue providing other services besides COVID-19 and ensure continuity of services' (p. 13). ${ }^{24}$

\section{Re-purposing of available services and establishing a dedicated} isolation centre

One study reported that existing health services had been re-arranged to suit healthcare workers capability and treatment administration. The re-purposing of existing services involved, among others, providing health services 
for COVID-19 suspected cases through dedicated clinical units, establishing isolation centres and providing protective masks. ${ }^{25}$

\section{DISCUSSION}

Our scoping review provided comprehensive information on Africa's health system preparedness, impact and responses to the pandemic. While Africa's weak healthcare system is already well recognised, our findings identified three core preparedness-related bottlenecks. These included the lack of resources and equipment, limited testing ability and inadequate surge capacity to deal with COVID-19. Our results identified several impacts attributed to the pandemic, including reduced service utilisation rates and missing scheduled appointments by chronic care patients. Despite the negative consequences, some response measures such as availing telephone consultations, re-purposing of services and facilities and establishing isolation centres and provisions of guidelines were in place as response mechanisms. However, in some settings, some services remained unaffected.

COVID-19 pandemic has challenged local, national, regional and global capacities to prepare and respond. ${ }^{46}$ Recent pandemics, such as COVID-19 and others like the HIV epidemic of the early 1990s and the Ebola outbreak in the mid-2010s, have presented significant challenges to the African health systems. ${ }^{48}$ Several countries have learnt valuable lessons from these crises and developed coping mechanisms to combat these diseases. ${ }^{49}$ Various experts have speculated the potential impact of the COVID-19 pandemic in the African health systems early in the pandemic and alerted resource-limited countries to make the utmost preparation to lessen the impact of the pandemic. ${ }^{50-52}$ Also, lessons from outside the region were essential for controlling the spread of COVID-19. For example, during the early phase of the outbreak, some countries such as China quickly deployed human resources and expanded infrastructure, including constructing two new hospitals and re-designated wards in existing hospitals to isolate and treat patients immediately, ${ }^{53}$ although the applicability of such aggressive measures remains a moot point in resource-limited countries. These being the case, the late introduction of COVID-19 into the African continent has offered an opportunity for the region to develop testing and treatment capabilities strategies. ${ }^{54}$ This was evident from the number of countries that could undertake laboratory tests increased from only 2 (South Africa and Senegal) in January 2020 to 33 in a few months following the advent of the pandemic in the region. ${ }^{55}$ Some countries achieved this by re-purposing existing research laboratories, diagnostic tools and reagents previously used for other infectious diseases. ${ }^{56}$ However, disruption in the supply chain of highly needed resources such as PPE and increased global demand ${ }^{58} 59$ meant vast shortages of such equipment in many countries globally, including African countries. ${ }^{60}$ It was not surprising that our review showed the lack of resources and equipment and limited know-how and surge capacity for COVID-19 in these countries. Several countries reported inadequate supply of PPE equipment and essential medicines. ${ }^{61}$ Moreover, the challenges became even more apparent when some African countries such as Kenya embarked on mass testing, ${ }^{62}$ despite shortages of test kits. ${ }^{63}$ In part, this problem was exacerbated by travel restrictions ${ }^{59}$ that hindered international trade, particularly the ability to purchase new equipment or transport donated materials.

Our review showed that the pandemic impacted essential and general health services, leading to reduced flow of patients, missed scheduled appointments and lower hospital admission rates. These findings were consistent with a recent time-series study in China that reported a significant decline in inpatient and outpatient visits. ${ }^{64}$ Apart from essential healthcare services, healthcare services dedicated to non-communicable diseases were also impacted, partly due to priorities accorded to acute cases and to the COVID-19 pandemic. This was observed in a study from Morocco that reported a significant decline in cancer patients admission in the early phases of the lockdown. ${ }^{25}$ The study result was consistent with a report from the WHO indicating a considerable degree of healthcare services disruption for non-communicable diseases in the early phases of the pandemic in more than three-quarters of countries globally. ${ }^{65}$ Similarly, although not directly comparable as most studies in the reviews came from high-income settings, two reviews showed adverse effects of COVID-19 on hospital visits, hospitalisations, diagnostics, and maternal and child health services. $^{1966}$ Furthermore, the current study showed that the pandemic had also affected the mental health status of healthcare workers due to fear of infection and work-related stress. The findings from Africa were consistent with those from Thailand, which revealed that the COVID-19 pandemic led to uncertainty, anxiety, fear and stigmatisation among healthcare workers. ${ }^{67}$ However, our review noted that not all health services were affetcted as demonstrated from studies conducted from Ethiopia and Uganda. ${ }^{1630}$ While this could partly be explained due to that some of the studies included in our review conducted in earlier phases of the pandemic, it may also reflect the attention provided to preserve the provision of essential health services in some settings, which needs further research.

Our study has also indicated some variations on the impact of COVID-19 between geographic locations, vulnerable populations and countries. For example, our findings from a Tanzanian study ${ }^{26}$ indicated that there were disparities in the level of health facility readiness for COVID-19 prevention measures as urban facilities were two times better than their rural counterparts in terms of available functioning communication systems.

\section{Implication for policy and future research}

The African health systems will continue to be confronted by emerging global and local events, including conflict, a 
potential new infectious disease, climate change and the increasing burden of non-communicable diseases. On another side, countries with a fragile health system are likely to be overwhelmed by the complexity of case identification, the need to establish and maintain communication strategies, and the challenges of safely caring for a surge of critically ill patients. ${ }^{68}$ Ultimately, the focus in the region should be on creating a resilient health system, a system that responds for all health challenges, times and people. ${ }^{69}$ Well-established and resilient health system allows countries to prepare and respond appropriately to health system shocks and disturbances following unprecedented community health risks, including pandemics. ${ }^{46}$ However, establishing a resilient health system will not be without challenges, partly due to limited resources, including insufficient health financing and shortage of skilled health workforce. While COVID-19 remains a biomedical challenge, an approach focused on disease control alone will be insufficient to contain the pandemic. ${ }^{70}$ Lesson from past epidemics and major health challenges in the region remind us of the need to protect, support and empower the frontline healthcare workers, particularly the community health workforce, which remains the backbone of Africa's health system. ${ }^{71}$

With the advent of COVID-19 vaccines, vaccination roll-out can serve as one pillar of the health systems response globally and in Africa. ${ }^{72}$ Just in less than a year, we observed several success stories in vaccination coverage, mainly in high-income countries, including a coverage rate of over $85 \%$ in Portugal and the UAE. ${ }^{73}$ In countries like Portugal, such success led to getting away with lockdowns or wearing masks outdoors. ${ }^{74}$ Unfortunately, many countries in Africa are still at the bottom lane of the queue for vaccination access except Seychelles, which achieved a vaccination roll-out of over $75 \%$ of its population. ${ }^{73}$ The COVAX initiative, a multilateral coalition led by GAVI, the Vaccine Alliance, the Coalition for Epidemic Preparedness Innovations, and the WHO, was established to facilitate life-saving COVID-19 vaccines to low-income countries. ${ }^{75}$ However, despite the pledges to allocate sufficient doses for 47 countries in Africa to vaccinate at least $20 \%$ of their population, the progress remains limited. ${ }^{76}$ Thus far, in Africa, only $5 \%$ of its population has received access to COVID-19 vaccines, which poorly compares with over $55 \%$ vaccination coverages in Australia and Europe, ${ }^{73}$ reflecting the continued disparities in equitable access to healthcare.

Unless vaccination access to the African countries is accelerated, the adverse impacts of COVID-19 identified in this review are likely to be further exacerbated as waves of existing and newly emerging variants of the COVID-19 hit the region. ${ }^{77} 78$ Therefore, African countries should focus on a coordinated approach to build capacity for vaccine development, transport and roll-out of vaccination for healthcare professionals and high-risk individuals, including rural areas. Even if these challenges are addressed through inter-African initiatives and cooperation with development partners, administering
Box 1 Implications for policy and research

Implications for health system policy

- Preparedness: Strengthen testing capacity and health emergency information system to ensure timely detection and response to new variants of COVID-19 and-as the pandemic matures and vaccine uptake increases-further integrate COVID-19 cases as part of a common notifiable disease.

- Impact: Moving toward a resilient health system responsive to emerging health threats and incorporating home care as part of the future pandemic impact response strategy.

- Response: Building human and infrastructure capacity and health financing mechanisms to ensure a sustainable supply and delivery of vaccines to eligible persons.

Implications for future research

- Systematic analysis of the impact of COVID-19 on:

- Specific health services (eg, surgical services).

- The role of the private health sector in ensuring public health security and emergency response.

- Health workers performance, with the latter being supported by qualitiave studies.

the new vaccines in each country could likely pose enormous logistical challenges for the region. For example, assuming a vaccination rate of $80 \%$ to achieve herd immunity for COVID-19, Africa will need to administer about a billion doses, which at the very least means doubling the region's vaccination capacity from its current level. Therefore, each African country will also have to develop the human resource need and infrastructural capabilities to vaccinate its population when the vaccines become available as desired. As the task is horrendous, countries must also intensify public awareness creation through active community engagement to reduce the burden of infection, debunk misinformation toward COVID-19 vaccination and improve Africa's health system ability to respond well with its limited capacity. Countries in the region also need to take the current challenge as an opportunity to develop a more resilient health system capacity through multilevel governance arrangements that coordinate local, national, regional and global actions. ${ }^{79}$ A well-established and resilient health system allows countries to prepare and respond appropriately to health system shocks and disturbances following unprecedented community health risks, including pandemics. ${ }^{46}$ Eventually, this will enable the health systems to minimise current COVID-19-related morbidity and mortality, maintain essential healthcare services, provide support for healthcare workers and effectively respond to subsequent waves of COVID-19 pandemic (see summary for implications for policy and research in box 1).

\section{Strengths and limitations}

Although two systematic reviews were conducted before the current study, the studies were mainly from highincome countries. ${ }^{18} 19$ Ours is the first study to provide an Africa focused comprehensive assessment of preparedness, impacts and responses to COVID-19 in the region. 
The integration of quantitative and qualitative studies is another strength of this review, which allowed to improve the volume of evidence and get multiple dimensions of the effects of the pandemic on Africa's health systems. However, the findings should not necessarily be taken as reflective of the views and perspectives in the African health systems in their entirety as we have only included two mixed-method studies and one qualitative study. Given that scoping reviews, by their nature, are focused on mapping rather than on appraising the quality of the available evidence, ${ }^{80}$ we have not performed quality appraisal in this review. In addition, we may have missed out on relevant studies published in other languages as the reviews in our paper were limited to those written in English. Despite the rigorous searching strategies that have been implemented in three broader bibliographic databases, our study might still have potentially missed out studies that could have been identified through other databases. Most of the included studies were based on data in the early stages of the pandemic. They may not be fully generalisable to or reflective of the everchanging situation in terms of the newly emerging variants of COVID-19 on a one side and the development of COVID-19 infection on the other side. We have not also explored the private health sector, particularly how it is affected by and its responses and role in fighting the pandemic. This remains a limitation as the private sector has a significant role in service delivery and can be a powerful partner if mobilised and provided the necessary government support.

\section{CONCLUSIONS}

The health systems in Africa were inadequately prepared for the pandemic, and its impact on other health services was substantial. The response to the pandemic was generally slow and did not correspond to the magnitude of the problem. Interventions that will improve and strengthen health system resilience through local, national and global engagement and improving healthcare financing should be given priority. High-quality time-trend analyses are needed to understand better the extent and nature of ongoing changes and responses of the African health systems to the pandemic.

\section{Author affiliations}

${ }^{1}$ Curtin School of Population Health, Curtin University, Perth, Western Australia, Australia

${ }^{2}$ School of Public Health, University of Adelaide, Adelaide, South Australia, Australia ${ }^{3}$ University of Canberra, Canberra, Australian Capital Territory, Australia

${ }^{4}$ College of Medicine, Qatar University, Doha, Qatar

${ }^{5}$ Department of Epidemiology and Biostatistics, Institute of Public Health, University of Gondar, Gondar, Ethiopia

${ }^{6}$ The George Institute for Global Health, University of New South Wales, Sydney, New South Wales, Australia

${ }^{7}$ School of Public Health, Mekelle University, Mekelle, Ethiopia

${ }^{8}$ School of Public Health, The University of Queensland, Brisbane, Queensland, Australia

${ }^{9}$ Telethon Kids Institute, Perth, Western Australia, Australia

${ }^{10}$ Monash University, Clayton, Victoria, Australia

${ }^{11}$ School of Nursing, Mekelle University, Mekelle, Ethiopia
${ }^{12}$ Department of Pharmacy, University of New England, Armidale, New South Wales, Australia

${ }^{13}$ Department of Clinical Pharmacy, University of Gondar, Gondar, Ethiopia

${ }^{14}$ Faculty of Health, University of Tasmania, Hobart, Tasmania, Australia

${ }^{15}$ Research Centre for Generational Health and Ageing, University of Newcastle, Newcastle, New South Wales, Australia

${ }^{16}$ School of Public Health, College of Health and Medical Sciences, Haramaya University, Harar, Ethiopia

${ }^{17}$ Menzies Health Research Institute, Charles Darwin University, Darwin, Northern Territory, Australia

${ }^{18}$ School of Public Health, College of Medicine and Health Sciences, Hawassa University, Hawassa, Ethiopia

${ }^{19}$ Centre for Applied Health Economics, School of Medicine, Griffith University, Brisbane, Queensland, Australia

${ }^{20}$ Menzies Health Institute Queensland, Griffith University, Brisbane, Queensland, Australia

${ }^{21}$ Lifelong Health, South Australia Health and Medical Research Institute, Adelaide, South Australia, Australia

${ }^{22}$ College of Nursing and Health Sciences, Flinders University, Adelaide, South Australia, Australia

${ }^{23}$ Department of Pharmacology, School of Pharmacy, College of Health Sciences, Mekelle University, Mekelle, Ethiopia

${ }^{24}$ Division of Pharmacy, School of Allied Health, The University of Western Australia, Perth, Western Australia, Australia

${ }^{25}$ Population Child Health Research Group, School of Women's and Child Health, University of New South Wales, Sydney, New South Wales, Australia

${ }^{26}$ Public Health, College of Medicine and Public Health, Flinders University, Adelaide, South Australia, Australia

${ }^{27}$ Department of Epidemiology, School of Health Sciences, Mekelle University, Mekelle, Ethiopia

${ }^{28}$ Public Health, Debre Markos University, Debre Markos, Ethiopia

${ }^{29}$ Faculty of Health, University of Technology Sydney, Sydney, New South Wales, Australia

${ }^{30}$ College of Health Sciences, Debre Markos University, Debre Markos, Ethiopia

${ }^{31}$ School of Public Health, University of Technology Sydney, Sydney, New South Wales, Australia

${ }^{32}$ Maternal and Child Health, Federal Ministry of Health, Addis Ababa, Ethiopia

${ }^{33}$ Centre for Quality and Patient Safety Research, School of Nursing and Midwifery, Institute for Health Transformation, Deakin University, Burwood, VIC, Australia

${ }^{34}$ Department of Medicine, School of Clinical Sciences, Monash University, Clayton, VIC, Australia

${ }^{35}$ Ethiopian Public Health Institute, Addis Ababa, Ethiopia

${ }^{36}$ Institute for Health Metrics and Evaluation, University of Washington, Seattle, Washington, USA

${ }^{37}$ Vaccinology and Immunology Research Trials Unit, Women's and Children's Health Network, Adelaide, South Australia, Australia

${ }^{38}$ Robinson Research Institute, Adelaide Medical School, University of Adelaide, Adelaide, South Australia, Australia

${ }^{39}$ Deakin University, Institute of Health Transformation, Melbourne, Victoria, Australia

${ }^{40}$ Southgate Institute for Health, Society and Equity, Flinders University, Adelaide,

South Australia, Australia

Twitter Gizachew A Tessema @Giz_Tessema, Azeb Gebresilassie Tesema @Azebdej, Getiye Dejenu Kibret @GetiyeKibret and Cheru Tesema Leshargie @Chertb19

Contributors GAT, YK, AGT, YA, AA, WMB, KG and FTH contributed to the concept, design and scope of this review. GAT, BAD, AGT, DE, KTG contributed to data extraction. GAT conducted data synthesis and wrote the first draft of the manuscript. All authors critically reviewed, edited and approved the final manuscript. GAT is the guarantor.

Funding GAT was supported with funding from the Australia National Health and Medical Research Council (NHMRC) Investigator Grant \#1195716.

Competing interests None declared.

Patient consent for publication Not applicable.

Provenance and peer review Not commissioned; externally peer reviewed.

Data availability statement All data relevant to the study are included in the article or uploaded as supplementary information. 
Supplemental material This content has been supplied by the author(s). It has not been vetted by BMJ Publishing Group Limited (BMJ) and may not have been peer-reviewed. Any opinions or recommendations discussed are solely those of the author(s) and are not endorsed by BMJ. BMJ disclaims all liability and responsibility arising from any reliance placed on the content. Where the content includes any translated material, BMJ does not warrant the accuracy and reliability of the translations (including but not limited to local regulations, clinical guidelines, terminology, drug names and drug dosages), and is not responsible for any error and/or omissions arising from translation and adaptation or otherwise.

Open access This is an open access article distributed in accordance with the Creative Commons Attribution Non Commercial (CC BY-NC 4.0) license, which permits others to distribute, remix, adapt, build upon this work non-commercially, and license their derivative works on different terms, provided the original work is properly cited, appropriate credit is given, any changes made indicated, and the use is non-commercial. See: http://creativecommons.org/licenses/by-nc/4.0/.

\section{ORCID iDs}

Gizachew A Tessema http://orcid.org/0000-0002-4784-8151

Azeb Gebresilassie Tesema http://orcid.org/0000-0003-0618-4499

Yibeltal Assefa http://orcid.org/0000-0003-2393-1492

Maereg Wagnew Meazew http://orcid.org/0000-0001-7254-7468

\section{REFERENCES}

1 Olum R, Chekwech G, Wekha G, et al. Coronavirus disease-2019: knowledge, attitude, and practices of health care workers at Makerere university teaching hospitals, Uganda. Front Public Health 2020;8:181.

2 World Health Organization. Coronavirus disease 2019 (COVID-19) situation report - 51. Coronavirus disease (COVID-2019) situation reports. Geneva: WHO, 2020.

3 Our World in Data. Statistics and research: coronavirus (COVID-19) pandemic 2021. Available: https://ourworldindata.org/covid-cases [Accessed 26 Oct 2021].

4 El-Sadr WM, Justman J. Africa in the path of Covid-19. N Engl J Med Overseas Ed 2020;383:e11.

5 Hopman J, Allegranzi B, Mehtar S. Managing COVID-19 in low- and middle-income countries. JAMA 2020;323:1549-50.

6 World health Organization. World health organisation, coronavirus disease 2019 (COVID-19): situation report 46. Geneva: WHO, 2020.

7 World Health Organization. Infection prevention and control during health care when novel coronavirus (nCoV) infection is suspected: interim guidance, 25 January 2020. World Health Organization, 2020

8 Gele A. What works where in prevention of Covid-19: the case of Somalia. East Mediterr Health J 2020;26:495-6.

9 Gilbert M, Pullano G, Pinotti F, et al. Preparedness and vulnerability of African countries against importations of COVID-19: a modelling study. Lancet 2020;395:871-7.

10 Ihekweazu C, Agogo E. Africa's response to COVID-19. BMC Med 2020;18:151

11 Paintsil E. COVID-19 threatens health systems in sub-Saharan Africa: the eye of the crocodile. J Clin Invest 2020;130:2741-4.

12 Nkengasong JN, Mankoula W. Looming threat of COVID-19 infection in Africa: act collectively, and fast. Lancet 2020;395:841-2.

13 Ditekemena JD, Nkamba DM, Muhindo HM, et al. Factors associated with adherence to COVID-19 prevention measures in the Democratic Republic of the Congo (DRC): results of an online survey. BMJ Open 2021;11:e043356.

14 Shewasinad Yehualashet S, Asefa KK, Mekonnen AG, et al. Predictors of adherence to COVID-19 prevention measure among communities in North Shoa Zone, Ethiopia based on health belief model: a cross-sectional study. PLoS One 2021;16:e0246006.

15 Bruine de Bruin W, Bennett D. Relationships between initial COVID-19 risk perceptions and protective health behaviors: a national survey. Am J Prev Med 2020;59:157-67.

16 Abdela SG, Berhanu AB, Ferede LM, et al. Essential healthcare services in the face of COVID-19 prevention: experiences from a referral hospital in Ethiopia. Am J Trop Med Hyg 2020;103:1198-200.

17 Lassi ZS, Naseem R, Salam RA, et al. The impact of the COVID-19 pandemic on immunization campaigns and programs: a systematic review. Int J Environ Res Public Health 2021;18:1-19.

18 Kotlar B, Gerson E, Petrillo S, et al. The impact of the COVID-19 pandemic on maternal and perinatal health: a scoping review. Reprod Health 2021;18:10.

19 Bolarinwa OA, Ahinkorah BO, Seidu A-A, et al. Mapping evidence of impacts of COVID-19 outbreak on sexual and reproductive health: a scoping review. Healthcare 2021;9:436.
20 Arksey H, O'Malley L. Scoping studies: towards a methodological framework. Int J Soc Res Methodol 2005;8:19-32.

21 Levac D, Colquhoun H, O'Brien KK. Scoping studies: advancing the methodology. Implement Sci 2010;5:69.

22 Joanna Briggs Institute. Systematic review resource package. Adelaide: The Joanna Briggs Institute, 2015.

23 Tricco AC, Lillie E, Zarin W, et al. PRISMA extension for scoping reviews (PRISMA-ScR): checklist and explanation. Ann Intern Med 2018;169:467-73.

24 Ahmed SAKS, Ajisola M, Azeem K, et al. Impact of the societal response to COVID-19 on access to healthcare for non-COVID-19 health issues in slum communities of Bangladesh, Kenya, Nigeria and Pakistan: results of pre-COVID and COVID-19 lockdown stakeholder engagements. BMJ Glob Health 2020;5.

25 Ammor YM, Kaiïtouni ZI, Darfaoui M, et al. Managing cancer patients during COVID-19 pandemic: a North African oncological center experience. Pan Afr Med J 2020;35:144.

26 Bajaria S, Abdul R. Preparedness of health facilities providing HIV services during COVID-19 pandemic and assessment of their compliance to COVID-19 prevention measures: findings from the Tanzania Service Provision Assessment (SPA) survey. Pan Afr Med J 2020;37:18.

27 Barasa EW, Ouma PO, Okiro EA. Assessing the hospital surge capacity of the Kenyan health system in the face of the COVID-19 pandemic. PLoS One 2020;15:e0236308.

28 Bell D, Hansen KS, Kiragga AN, et al. Predicting the impact of COVID-19 and the potential impact of the public health response on disease burden in Uganda. Am J Trop Med Hyg 2020;103:1191-7.

29 Buonsenso D, Cinicola B, Kallon MN, et al. Child healthcare and immunizations in sub-Saharan Africa during the COVID-19 pandemic. Front Pediatr 2020;8:517.

30 Burt JF, Ouma J, Lubyayi L, et al. Indirect effects of COVID-19 on maternal, neonatal, child, sexual and reproductive health services in Kampala, Uganda. BMJ Glob Health 2021;6:e006102.

31 Debes JD, Quadri NS, Sultan A, et al. Risk of healthcare worker burnout in Africa during the covid-19 pandemic. Ann Glob Health 2021;87:5-4

32 Deressa W, Worku A, Abebe W, et al. Risk perceptions and preventive practices of COVID-19 among healthcare professionals in public hospitals in Addis Ababa, Ethiopia. PLoS One 2021:16:e0242471.

33 Desalegn Z, Deyessa N, Teka B, et al. Evaluation of COVID-19 related knowledge and preparedness in health professionals at selected health facilities in a resource-limited setting in Addis Ababa, Ethiopia. PLoS One 2021;16:e0244050.

34 Gichuna S, Hassan R, Sanders T, et al. Access to healthcare in a time of COVID-19: sex workers in crisis in Nairobi, Kenya. Glob Public Health 2020;15:1430-42.

35 Jensen C, McKerrow NH. Child health services during a COVID-19 outbreak in KwaZulu-Natal Province, South Africa. S Afr Med J;2021:114-9.

36 Mohammed H, Oljira L, Roba KT, et al. Containment of COVID-19 in Ethiopia and implications for tuberculosis care and research. Infect Dis Poverty 2020;9:131.

37 Odume B, Falokun V, Chukwuogo O, et al. Impact of COVID-19 on TB active case finding in Nigeria. Public Health Action 2020;10:157-62.

38 Otitoloju AA, Oluwole EO, Bawa-Allah KA. Preliminary evaluation of COVID-19 disease outcomes, test capacities and management approaches among African countries. medRxiv 2020;20103838.

39 Pierre G, Uwineza A, Dzinamarira T. Attendance to HIV antiretroviral collection clinic appointments during COVID-19 Lockdown. A single center study in Kigali, Rwanda. AIDS Behav 2020;24:3299-301.

40 Sagaon-Teyssier L, Kamissoko A, Yattassaye A, et al. Assessment of mental health outcomes and associated factors among workers in community-based HIV care centers in the early stage of the COVID-19 outbreak in Mali. Health Policy Open 2020;1:100017.

41 Schwartz JI, Muddu M, Kimera I, et al. Impact of a COVID-19 national lockdown on integrated care for hypertension and HIV. Glob Heart 2021;16:9.

42 Semaan A, Audet C, Huysmans E. Voices from the frontline: findings from a thematic analysis of a rapid online global survey of maternal and newborn health professionals facing the COVID-19 pandemic. BMJ Glob Health 20202020;520093393.

43 Shikuku D, Nyaoke I, Gichuru S. Early indirect impact of COVID-19 pandemic on utilization and outcomes of reproductive, maternal, newborn, child and adolescent health services in Kenya. medRxiv 2020;20191247.

44 Siedner MJ, Kraemer JD, Meyer MJ, et al. Access to primary healthcare during lockdown measures for COVID-19 in rural 
South Africa: an interrupted time series analysis. BMJ Open 2020;10:e043763.

45 Mbunge E. Effects of COVID-19 in South African health system and society: an explanatory study. Diabetes Metab Syndr 2020;14:1809-14.

46 Haldane V, De Foo C, Abdalla SM, et al. Health systems resilience in managing the COVID-19 pandemic: lessons from 28 countries. Nat Med 2021;27:964-80.

47 Buseh AG, Stevens PE, Bromberg M, et al. The Ebola epidemic in West Africa: challenges, opportunities, and policy priority areas. Nurs Outlook 2015;63:30-40.

48 Schneider H, Blaauw D, Gilson L, et al. Health systems and access to antiretroviral drugs for HIV in Southern Africa: service delivery and human resources challenges. Reprod Health Matters 2006;14:12-23.

49 Bell BP, Damon IK, Jernigan DB, et al. Overview, control strategies, and lessons learned in the CDC response to the 2014-2016 Ebola epidemic. MMWR Suppl 2016;65:4-11.

50 Divala T, Burke RM, Ndeketa L, et al. Africa faces difficult choices in responding to COVID-19. Lancet 2020;395:1611.

51 Jewell BL, Mudimu E, Stover J, et al. Potential effects of disruption to HIV programmes in sub-Saharan Africa caused by COVID-19: results from multiple mathematical models. Lancet HIV 2020; $7:$ :e629-40.

52 Nachega JB, Kapata N, Sam-Agudu NA, et al. Minimizing the impact of the triple burden of COVID-19, tuberculosis and HIV on health services in sub-Saharan Africa. Int J Infect Dis 2021 doi:10.1016/j. ijid.2021.03.038

$53 \mathrm{Wu}$ Z, McGoogan JM. Characteristics of and important lessons from the coronavirus disease 2019 (COVID-19) outbreak in China: summary of a report of 72314 cases from the Chinese center for disease control and prevention. JAMA 2020;323:1239-42.

54 Massinga Loembé M, Tshangela A, Salyer SJ, et al. COVID-19 in Africa: the spread and response. Nat Med 2020;26:999-1003.

55 Elbany M, Elhenawy Y. Analyzing the ultimate impact of COVID-19 in Africa. Case Stud Transp Policy 2021;9:796-804.

56 Okoth EA, Oyola S. Re-purposing ILRI labs to support national COVID-19 testing in Kenya, 2020.

57 Peplow M. Developing countries face diagnostic challenges as the COVID-19 pandemic surges. Chem Eng News 2020.

58 Park C-Y, Kim K, Roth S. Global shortage of personal protective equipment amid COVID-19: supply chains, bottlenecks, and policy implications. Asian Development Bank, 2020.

59 Guan D, Wang D, Hallegatte S, et al. Global supply-chain effects of COVID-19 control measures. Nat Hum Behav 2020;4:577-87.

60 World Health Organization. Shortage of personal protective equipment endangering health workers worldwide, 2020.

61 Ranney ML, Griffeth V, Jha AK. Critical supply shortages - the need for ventilators and personal protective equipment during the Covid-19 pandemic. N Engl J Med 2020;382:e41.

62 Xinhua. Kenya embarks on mass testing for COVID-19 English, 2020. Available: http://www.xinhuanet.com/english/2020-03/29/c_ 138928882.htm14 [Accessed Jul 2021].

63 Kobia F, Gitaka J. COVID-19: are Africa's diagnostic challenges blunting response effectiveness? AAS Open Res 2020;3:4.
64 Xiao H, Dai X, Wagenaar BH. The impact of the COVID-19 pandemic on health services utilization in China: time-series analyses for 2016-2020. Lancet Reg Health West Pac 2021;9.

65 World Health Organization. The impact of the COVID-19 pandemic on noncommunicable disease resources and services: results of a rapid assessment. Geneva: WHO, 2020. https://www.who.int/ publications/i/item/9789240010291

66 Moynihan R, Sanders S, Michaleff ZA, et al. Impact of COVID-19 pandemic on utilisation of healthcare services: a systematic review. BMJ Open 2021;11:e045343.

67 Nochaiwong S, Ruengorn C, Awiphan R, et al. Mental health circumstances among health care workers and general public under the pandemic situation of COVID-19 (HOME-COVID-19). Medicine 2020;99:e20751.

68 Nuzzo JB, Meyer D, Snyder M, et al. What makes health systems resilient against infectious disease outbreaks and natural hazards? Results from a scoping review. BMC Public Health 2019;19:1310-10.

69 Gebremeskel AT, Otu A, Abimbola S, et al. Building resilient health systems in Africa beyond the COVID-19 pandemic response. BMJ Glob Health 2021;6:e006108.

70 Mathpati MM, Payyappallimana U, Shankar D. 'Population self-reliance in health' and COVID 19: the need for a 4(th) tier in the health system. J Ayurveda Integr Med 2020 doi:10.1016/j. jaim.2020.09.003

71 Ballard M, Bancroft E, Nesbit J, et al. Prioritising the role of community health workers in the COVID-19 response. BMJ Glob Health 2020;5:e002550.

72 Boum li Y, Ouattara A, Torreele E, et al. How to ensure a needsdriven and community-centred vaccination strategy for COVID-19 in Africa. BMJ Glob Health 2021;6:e005306.

73 Coronavirus (COVID-19) Vaccinations. Share of people vaccinated against COVID-19: our world in data, 2021. Available: https:// ourworldindata.org/covid-vaccinations [Accessed 26 Oct 2021].

74 The National Herald. Portugal: wearing face masks outdoors no longer mandatory LISBON, Portugal the National Herald, 2021. Available: https://www.thenationalherald.com/coronavirus/arthro/ portugal wearing face masks outdoors no longer_mandatory3231227/ [Accessed 26 Oct 2021].

75 WHO. COVAX: working for global equitable access to COVID-19 vaccines, 2021. Available: https://www.who.int/initiatives/actaccelerator/covax21

76 WHO. COVID-19 vaccines, 2021. Available: https://www. afro. who int/health-topics/coronavirus-covid-19/vaccines [Accessed 21 Oct 2021].

77 Salyer SJ, Maeda J, Sembuche S, et al. The first and second waves of the COVID-19 pandemic in Africa: a cross-sectional study. Lancet 2021;397:1265-75.

78 WHO Regional Office for Africa. COVID-19 variants prolong Africa's pandemic wave, 2021. Available: https://www.afro.who.int/news/ covid-19-variants-prolong-africas-pandemic-wave22

79 Assefa Y, Gilks CF, van de Pas R, et al. Reimagining global health systems for the 21 st century: lessons from the COVID-19 pandemic. BMJ Glob Health 2021;6:e004882.

80 Munn Z, Peters MDJ, Stern C, et al. Systematic review or scoping review? Guidance for authors when choosing between a systematic or scoping review approach. BMC Med Res Methodol 2018:18:143. 